\title{
Correction to: Hemagglutinin Inhibitors are Potential Future Anti-Influenza Drugs for Mono- and Combination Therapies Nongluk Sriwilaijaroen and Yasuo Suzuki
}

\section{Correction to:}

Chapter 48 in: Jun Hirabayashi (ed.), Lectin Purification and Analysis:

Methods and Protocols, Methods in Molecular Biology, vol. 2132,

https://doi.org/10.1007/978-1-0716-0430-4_48

The inadvertently published below contents have been corrected.

1. In the opening page the organisational email address has been added below the authors name in the chapter opening page.

2. In table 1 in page 552, one of the two overlapping structures have been removed.

3 . In table 1 in page 556, two repeated structures have been removed.

The updated online version of this chapter can be found at https://doi.org/10.1007/978-1-0716-0430-4_48 